\title{
Assessment of the Spread of Chestnut Ink Disease from 1995 to 2005 Using Aerial Photography and Geostatistical Methods
}

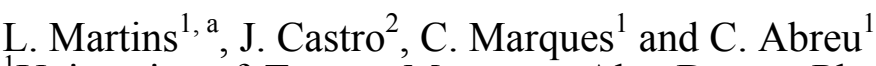 \\ ${ }^{1}$ University of Tras-os-Montes e Alto Douro, Plant Protection Department, Vila Real, \\ 5000-911, Portugal \\ ${ }^{2}$ Escola Superior Agraria, Braganca, 5301-855, Portugal
}

Keywords: aerial photography, Castanea sativa, kriging interpolation, Phytophthora cinnamomi

\begin{abstract}
Chestnut ink disease, caused by Phytophthora cinnamomi and P. cambivora, is responsible for important economic losses and it limits the establishment of new chestnut (Castanea sativa) groves in Portugal. Differences in soil properties and in cropping practices affect the Ink severity, and differences on levels of attacks can be assessed by remote sensing. In this study data for monitoring $C$. sativa decline was selected using field surveys and aerial photography: Near-infrared images obtained in 1995 and normal and false color images obtained in 2005. The spatial distribution of Ink Disease in Northern Portugal for the years 1995-2005 was estimated through kriging interpolation. From 1995 to 2005 chestnut area in Portugal declined due to the fact that new plantations $(\mathbf{1 5 . 0 \% )}$ were not sufficient to replace chestnut mortality (26.9\%). The foci and the spread of the disease have increased since 1995. Also, the average damage level has significantly different in observations for the two dates.
\end{abstract}

\section{INTRODUCTION}

The rising demand for sweet chestnut (Castanea sativa Mill.), in Portugal and elsewhere in Europe, has led to more intensive management practices in order to increase nut production. These include mineral fertilization and increasing the use of pruning, which have progressively replaced traditional farmyard manure (Portela et al., 1998). However, in Portugal, the current widespread incidence of the Ink Disease caused by Phytophthora cinnamomi Rands (occasionally by P. cambivora (Petri) Buis.) leads to important losses in chestnut production and limits the establishment of new planted areas (Abreu, 1992; Martins et al., 1999).

Some chestnut groves affected by Ink Disease can be found near healthy trees and also grouped in clusters. This suggests that bad soil conditions and the interaction between site factors and cropping practices can contribute to disease incidence (Portela et al., 1998). Soil compaction associated with those practices also stimulates the $P$. cinnamomi development (Fonseca et al., 2004). The unregulated search for wild mushrooms can also reduce chestnut tree resistance due to the ectomycorrhyizal fungi reduction (Bärtschi et al., 1981; Branzanti et al., 1994; Brasier et al., 1993; Martins et al., 1999). However, the widespread incidence on a large scale, and the causes that affect the disease spread, are not well known. That's why the monitoring of plant health is so important.

Monitoring chestnut health requires simple methods of damage evaluation because, under favourable conditions, the disease rapidly spreads by zoospores and chlamydospores through water and movement of soil particles (Zentmyer, 1980). Control of Ink Disease is based on preventive measures that should be applied at a regional scale in order to be effective. As a consequence, an efficient monitoring system capable of providing information of the number and size of infected foci is necessary (Vannini et al., 2005). Aerial photography can also be useful to detect chestnut - blight foci (Bissegger and Heiniger, 1994) a relatively recent disease in Portugal but with a high spread in the

almartins@utad.pt 
last few years.

The quantification of ink disease symptoms were made by Martins et al. (2001, 2007) using Small Format Aerial Photography (SFAP) and Conventional Aerial Photography (CAP). The discrimination of chestnut health conditions were also done successfully with SFAP by Ambrosini et al. (1997).

The spread of Ink Disease can be estimated by spatial interpolation methods, due to its relation with geographical variables such as soil and climatic characteristics (Martins et al., 2005, 2007). The Krige interpolation method was originally developed for gold prospecting in South African mines (Krige, 1951). This method interpolates spatial data and allows for great flexibility in defining the interpolation model, according to field information. It is based in a semivariogram, i.e., a mathematical model for describing the spatial variability of the geographical data. The semivariogram is represented as a graph with $\mathrm{X}$-axis showing the separation distances between observed trees (lags). The Y-axis showing the average variability of sample data pairs for each lag distance (Cressie, 1986).

The spread of Ink Disease can also be carried out on pairs of sample data points $\left(x-x^{\prime}\right)$. Every data point (health data) is paired with every other data point. Each pair is characterized by its separation distance (lag) and direction (Goovaerts, 1999).

In the present study conventional aerial images was used to monitor chestnut decline since 1995. The distribution of Ink Disease was mapped using the geostatistical method known as ordinary kriging (Cressie, 1986). The purpose of this paper is to describe and discuss the results obtained using those two methods.

\section{MATERIALS AND METHODS}

A study site in the Padrela Region of Northern Portugal was selected for its high incidence of the chestnut Ink Disease (Martins et al., 2001, 2005). The site area $(12,162$ ha) has a Mediterranean climate and chestnut orchards of different ages, from newly planted trees to trees of 30-40 years old (adult trees). The study area is located in a mountain region at altitudes between 400 and $900 \mathrm{~m}$, between the UTM coordinates (29T, North) $X, Y=623,4614 \mathrm{~km}$ and $X, Y=636,4593 \mathrm{~km}$.

The geographical data was processed in a Geographical Information System (GIS). The chestnut area cartography was draw using Conventional CIR aerial photography $(23 \times 23 \mathrm{~cm}$ format $)$ obtained in 1995 . A $100 \times 100 \mathrm{~m}$ grid was considered to randomly select 203 circular permanent sampling plots, with an area of $1250 \mathrm{~m}^{2}$ each. A total of 2468 chestnut trees in the sampling plots were visually evaluated on computer screen, according to the structural and chromatic characteristics of the chestnut canopies. Five damage levels were considered, using the European and standardized criteria (Cadahia et al., 1991): $0=$ healthy tree $(0-10 \%$ canopy defoliation); $1=$ slightly damaged ( $11-25 \%$ canopy defoliation); $2=$ moderately damaged (26-60\% canopy defoliation); $3=$ heavily damaged (61-90\% canopy defoliation); 4=dead tree.

The Portuguese authority for forestry - DGRF (Direcção Geral dos Recursos Florestais), performed in 2005 the fifth revision of the National Forest Inventory. For the first time in Portugal, the aerial photographic coverage was acquired in digital format. The whole country was covered and orthophotos were produced from these images to be used in the updating of the national forest inventory. The images were taken with a digital aerial camera Vexcel UltraCamD from a flying height of about $5600 \mathrm{~m}$ and have a ground sample distance (GSD) of $50 \mathrm{~cm}$. The multiple CCD is capable to detect visual and infrared radiation (Lumme, 2006; Redweik and Crispim, 2007; Raggam and Gutjahr, 2007; http://www.microsoft.com/ultracam, accessed on May, 2008).

Both images, normal and false colour, were used to quantify the damage scale of the trees. The mortality, and the new chestnut planted trees, were also quantified on sampling permanent plots (Fig. 1). The new trees were not evaluated on damage level due to the small dimension of the canopy.

The accuracy of image interpretation was improved by field assessment (Martins et al., 2001, 2005).

The spatial interpolation of the chestnut health data was determined by a 
theoretical spherical model (Equation 1), adjusted to an empirical semivariogram (Equation 2). In equations 1 and 2, $n(h)$ represents the number of pairs of trees with lag distance $h, Z\left(x_{i}\right)$ represents the health condition for each location $x_{i}$ and $a$ represents the range, i.e., the greater lag distance in the model (Cressie, 1988).

$$
\gamma(h)=\left\{\begin{array}{l}
C\left[\frac{3}{2} \frac{h}{a}-\frac{1}{2}\left(\frac{h}{a}\right)^{3}\right] ; \text { when } h \leq a \\
C ; \text { when } h>a
\end{array}\right.
$$

$$
y(h)=\frac{1}{2 n(h)} \sum_{i=1}^{n(h)}\left[Z\left(\mathbf{x}_{\mathbf{i}}+\mathbf{h}\right)-Z\left(\mathbf{x}_{\mathbf{i}}\right)\right]^{2}
$$

The theoretical semivariogram $\gamma(h)$ was estimated from the empirical values $\gamma(h)$ considering 10 classes of lags $h$, by using a linear regression method.

Statistical analysis was performed using SPSS package program. Mean separation was tested by Duncan's multiple range test.

\section{RESULTS AND DISCUSSION}

The average damage levels in 1995 and 2005 were significantly different according to Duncan's multiple range test. The number of chestnut trees removed from the study area, mostly as a result of mortality through Ink Disease, has increased since 1995 (Fig. 2). From 1995 to 2005 chestnut area declined due to the fact that new plantations $(15.0 \%)$ were not sufficient to replace chestnut mortality $(26.9 \%)$.

By using only the 2005 aerial data, the average of damage is not significantly different from 1995 level. This occurs because the new chestnut plantations improve the global value, but do not reflect the real spread of the disease due to the chestnut trees previously removed are not counted.

The chestnut health data, adjusted on empirical semivariograms and in spherical models, showed several foci of P. cinnamomi incidence and areas without Ink Disease. This can be associated to the variability of the chestnut health condition caused by differences in cropping practices. The kriging interpolation also revealed that the most affected areas in 1995 had worsened during the following 10 years (Fig. 3).

The methodology presented in this paper proved to be effective in the diagnosis of the widespread occurrence, and can certainly be used in other countries. It was showed the advantages of monitoring the same chestnut plots in different years by using remote sensing (Fig. 1). Without this photographic data the field measurements would be incomplete.

Under the geostatistical approach, a variogram model needs to be selected, and this often requires rotations and transformations to account for anisotropy (Cressie and Chan, 1989). In this study, the disease spread obtained by ordinary kriging mostly occurs in areas with the same altitude where, generally, the soil tillage and human mobility are easier. As a result, the spread of Ink Disease may be primarily due to the transport of soil infested with chlamydospores and other inocula of Phytophthora species, which has also been reported by several authors (Abreu, 1992; Martins et al., 1999; Fonseca et al., 2004).

\section{Literature Cited}

Abreu, C.G. 1992. Chestnut ink disease: management practices and resistance. p.153-157. In: R.D. Wallace and L.G. Spinella (eds.), World Chestnut Industry Conference. Morgantown, West Virginia.

Ambrosini, I., Gherardi, L., Viti, M., Maresi, G. and Turchetti, T. 1997. Monitoring diseases of chestnut stands by small format aerial photography. Geocarto Internacional 12:41-46.

Bärtschi, H., Pearson, V.G. and Vegh, I. 1981. Vesicular-arbuscular mycorrhiza formation and root rot disease (Phytophthora cinnamomi) development in Chamaecyparis lawsoniana. Phytopathology 102:213-218.

Bissegger, M. and Heiniger, U. 1994. Aerial photographs reveal chestnut - blight foci. European Journal of Forest Pathology 24:419-423. 
Branzanti, M.B., Rocca, E. and Zambonelli, A. 1994. Influenza di funchi ectomicorrizici su Phytophthora cambivora e P. cinnamomi del castagno. Micologia Italiana 23:4752.

Brasier, C.M., Robredo, F. and Ferraz, J.P. 1993. Evidence for Phytophthora cinnamomi involvement in Iberian oak decline. Plant Pathology 42:140-145.

Cadahia, D.J., Cobos, M., Soria, S., Clauser, F., Gellini, R., Grossoni, P. and Ferreira, M.C. 1991. Observação de danos em espécies florestais mediterrâneas. Comissão das Comunidades Europeias, Ministério da Agricultura Pescas e Alimentação, Madrid p.96.

Cressie, N. 1986. Kriging nonstationary data. Journal of the American Statistical Association 395(81):625-63.

Cressie, N. 1988. Spatial prediction and ordinary kriging. Mathematical Geology 20:405421.

Cressie, N. and Chan, N.H. 1989. Spatial modelling of regional variables. Journal of the American Statistical Association 406(84):393-401.

Fonseca, T.F., Abreu, C.G. and Parresol, B.R. 2004. Soil compaction and chestnut ink disease. Forest Pathology 34:273-283.

Goovaerts, P. 1999. Geostatistics in soil science: state-of-the-art and perspectives. Geoderma 89:1-45.

Krige, D. 1951. A statistical approach to some mine valuation and allied problems on the Witwatersrand. Journal of the Chemical and Mining Society of South Africa 52:119139.

Lumme, J. 2006. Supervised classification using aerial photographs and lidar data. Center for Remote Sensing of Land Surfaces, Bonn, 28-30 September 2006. Helsinki University of Technology, Department of Surveying, Espoo, Finland.

Martins, L.M., Castro, J.P., Macedo, F.W., Marques, C.P. and Abreu, C.G. 2007. Assessment of the spread of chestnut ink disease using remote sensing and geostatistical methods. European Journal of Plant Pathology 119(2):159-164.

Martins, L.M., Lufinha, M.I., Marques, C.P. and Abreu, C.G. 2001. Small format aerial photography to assess Chestnut Ink Disease. Forest Snow and Landscape Research 73:357-360.

Martins, L.M., Macedo, F.W., Marques, C.P. and Abreu, C.G. 2005. Assessment of chestnut ink disease spread by geostatistical methods. Acta Hort. 693:621-625.

Martins, L.M., Oliveira, M.T. and Abreu, C.G. 1999. Soils and climatic characteristic of chestnut stands that differ on the presence of the ink disease. Acta Hort. 494:447-449.

Portela, E., Aranha, J., Martins, A. and Pires, A.L. 1998. Soil factors, farmer's practices and chestnut ink disease: some interactions. Acta Hort. 494:433-441.

Raggam, H. and Gutjahr, K. 2007. Comparative assessment of surface mapping procedures using images acquired by the digital high-resolution ultracamD camera. $27^{\text {th }}$ EARSel Symposium Geoinformation in Europe. June 4-7, 2007, Bozen/Bolzano, Italy.

Redweik, P. and Crispim, L. 2007. Direct georeferencing of digital camera images for stereo plotting. The International Archives of the Photogrammetry, Remote Sensing and Spatial Information Sciences 34:XXX.

Vannini, A., Vettraino, A.M., Fabi, A., Montaghi, A., Valentini, R. and Belli, C. 2005. Monitoring ink disease of chestnut with the airborne multispectral system A.S.P.I.S. Acta Hort. 693:529-533.

Zentmyer, G. 1980. Phytophthora cinnamomi and the diseases it causes. Monograph $\mathrm{n}^{\mathrm{o}}$ 10. The American Phytopathological Society, St. Paul, MN p.96. 


\section{$\underline{\text { Tables }}$}

Table 1. Health condition of chestnut trees evaluated from 1995 to 2005 in 203 sampling plots.

\begin{tabular}{lcccccc}
\hline Year/period & $\begin{array}{c}\text { Sampling } \\
\text { plots }\end{array}$ & Observed & $\begin{array}{c}\text { Chestnut tress } \\
\text { Mortality }\end{array}$ & $\begin{array}{c}\text { New plantations } \\
\text { (\%) }\end{array}$ & $\begin{array}{c}\text { Ave. of } \\
\text { the } \\
\text { damage }\end{array}$ & $\begin{array}{c}\text { Sampling } \\
\text { error } \\
(\%)\end{array}$ \\
\hline 1995 & 203 & 2192 & 5.8 & 3.8 & $1.40 \pm 0.10$ & 7.2 \\
$1996-2005$ & 203 & 2468 & 21.1 & 11.2 & $1.76 \pm 0.13$ & 7.3 \\
\hline Total: $1995-2005$ & & & 26.9 & 15 & - & - \\
\hline
\end{tabular}

\section{Figures}

1995

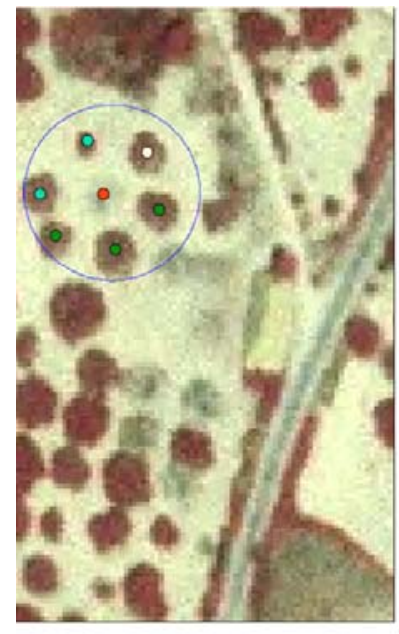

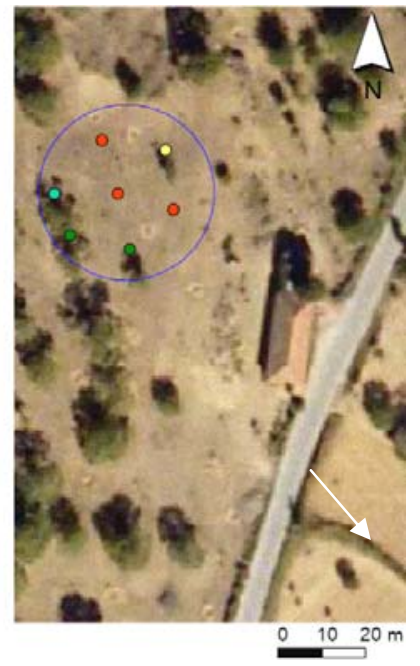

1996-2005

Level of damage

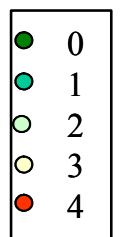

Fig. 1. Example of a sampling plot with chestnut damage level evaluation in a color infrared aerial photography (1995) and in a normal color aerial photography (2005). The arrow shows a new chestnut plantation established in the study period (1996-2005). 

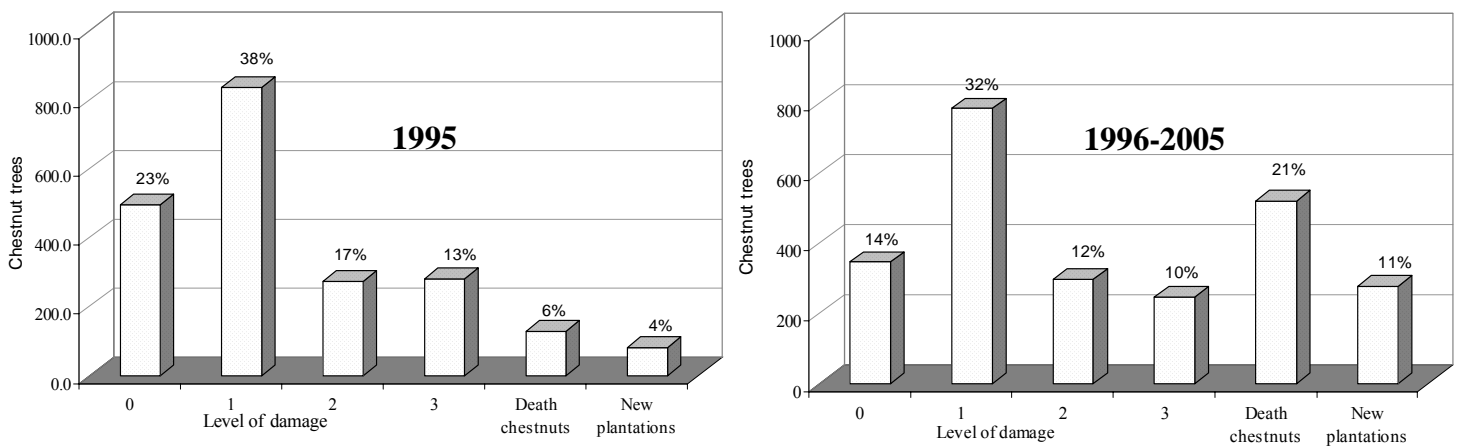

Fig. 2. Number of chestnut trees evaluated on sampling plots, divided according to the damage level, and new plantations on the same circular plots.
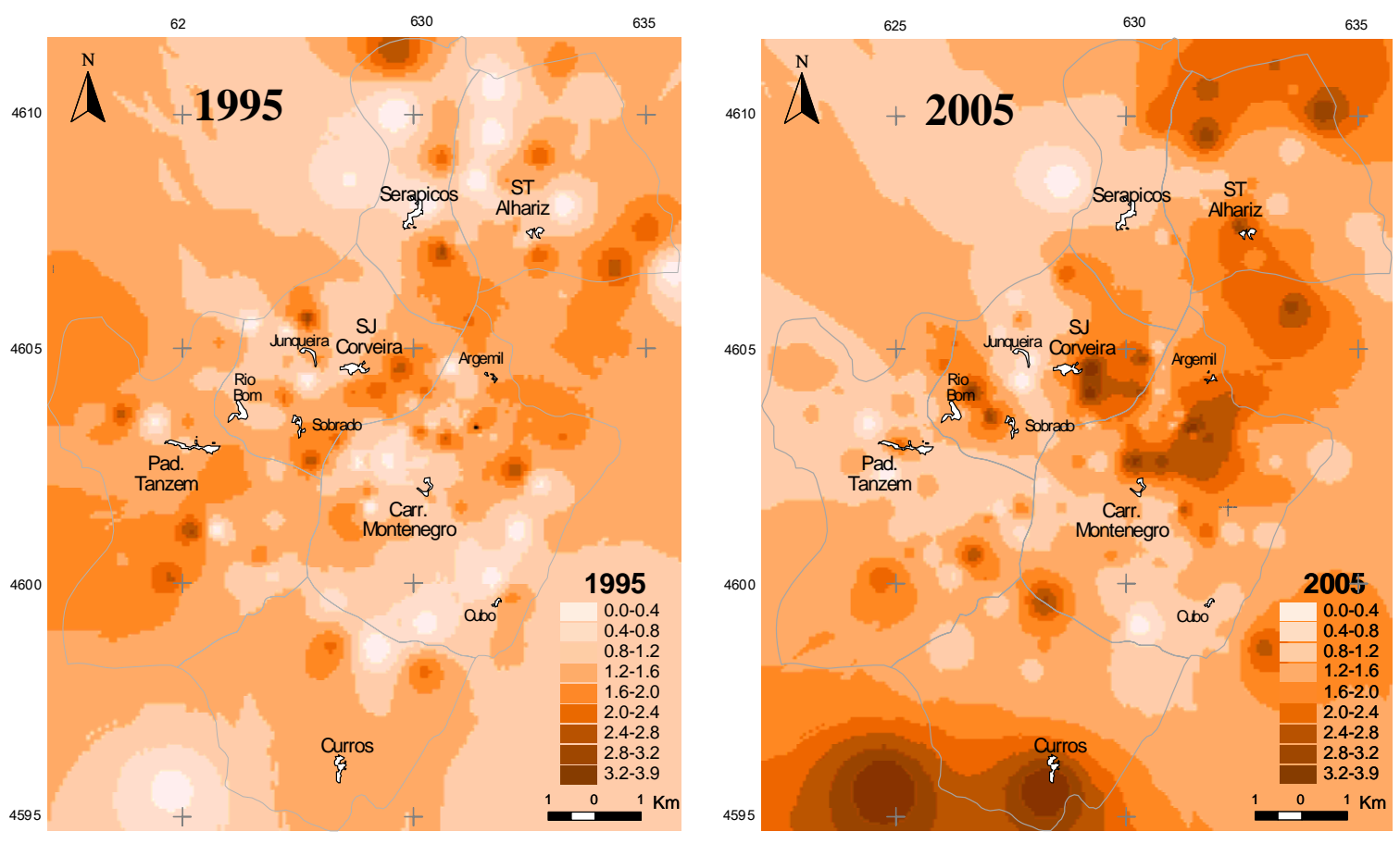

Fig. 3. Map of Ink disease spread from 1995 to 2005 obtained by ordinary kriging. The legend shows the damage level in each year. 